\title{
Removal of Diclofenac and Metformin from Water in Laboratory Photo Reactor ${ }^{\dagger}$
}

\author{
Anita Leovac Maćerak *, Đurđa Kerkez, Milena Bečelić-Tomin, Dragana Tomašević Pilipović, \\ Aleksandra Kulić, Jovana Jokić and Božo Dalmacija \\ Faculty of Sciences, University of Novi Sad, Novi Sad 21000, Serbia; djurdja.kerkez@dh.uns.ac.rs (Đ.K.); \\ milena.becelic-tomin@dh.uns.ac.rs (M.B.-T.); dragana.tomasevic@dh.uns.ac.rs (D.T.P.); \\ aleksandra.kulic@dh.uns.ac.rs (A.K.); jovanaj@dh.uns.ac.rs (J.J.); bozo.dalmacija@dh.uns.ac.rs (B.D.) \\ * Correspondence: anita.leovac@dh.uns.ac.rs; Tel.: +381-21-485-27-34 \\ + Presented at Environment, Green Technology and Engineering International Conference (EGTEIC 2018), \\ Caceres, Spain, 18-20 June 2018.
}

Published: 18 October 2018

\begin{abstract}
Diclofenac (DCF) and metformin (MET) are pharmaceuticals often detected in influents and effluents of municipal sewage treatment plants and surface waters which may cause adverse effects to human health and the environment. In recent years, advanced oxidation processes (AOPs) have been demonstrated to be effective technology for the removal of many organic pollutants. The objective of this study was to evaluate the removal and toxicity of investigated pharmaceuticals by $\mathrm{UV}$ and $\mathrm{UV} / \mathrm{H}_{2} \mathrm{O}_{2}$ processes. UV irradiation was provided by a Pen Ray lamp emission at $254 \mathrm{~nm}$ which was covered with a quartz tube and placed in the middle of the reactor. Experimental conditions of the process were: $[D I C, M E T]=10 \mathrm{mg} / \mathrm{L},\left[\mathrm{H}_{2} \mathrm{O}_{2}\right]=2.5 \mathrm{mM}$, reaction time $3 \mathrm{~h}$. Results obtained by only UV exposition of solution showed that diclofenac and metformin were degradated $30 \%$ and $50 \%$ during $3 \mathrm{~h}$ test. Addition of $2.5 \mathrm{mM} \mathrm{H}_{2} \mathrm{O}_{2}$ to photo reactor contributed to $90 \%$ and $100 \%$ removal of DCF and MET, respectively. Inhibition toxicity test of MET increased in the following range: $13 \%(\mathrm{C} 0)<38 \%(\mathrm{UV})<77 \%\left(\mathrm{UV} / \mathrm{H}_{2} \mathrm{O}_{2}\right)$, while toxicity measured for DCF solutions followed the range: $33 \%(\mathrm{UV})<75 \%(\mathrm{C} 0)<78 \%\left(\mathrm{UV} / \mathrm{H}_{2} \mathrm{O}_{2}\right)$. The results confirmed that addition of hydrogen-peroxide accelerated the removal of investigated pharmaceuticals, but at the same time, lead to formation of the more toxic intermediates. The possible reason for better removal efficiency of metformin can be related to its simpler aliphatic structure in comparison to more aromatic diclofenac.
\end{abstract}

Keywords: diclofenac; metformin; advanced oxidation processes; wastewater treatment

\section{Introduction}

Pharmaceuticals' increasing consumption and adverse effects on environment or human bodies have been attained extensive attention. Based on their uptake mechanism and route administration they are expelled as a mixture of metabolites, neutral substances, or conjugated complex with an inactivating compound attached to the molecule [1]. The emission of these emerging contaminants has emerged as an environmental problem and rather poor wastewater management could not effectively eliminate these compounds [2]. Diclofenac (DCF) is one of the most widely available nonsteroidal anti-inflammatory pharmaceuticals, which is included in the first "watch" list in order to gather monitoring data of priority substances in water [3]. Metformin (MET) is an oral antidiabetic pharmaceutical to treat type 2 diabetes and a potential anticancer agent. Metformin is not metabolized by the human body and is $100 \%$ excreted and as much as $70 \%$ through urine and the rest in feces [4]. Despite a large conversion in waste water treatment plants before discharge, 
metformin was still one of the most abundant pharmaceuticals found in WWTP effluents and surface waters [2].

In recent years, advanced oxidation processes (AOPs) have been demonstrated to be effective technology for the removal of many organic pollutants [5]. Among AOPs, Fenton-type reactions have been identified as effective methods which produce hydroxyl-radicals by the reaction between iron salts and hydrogen-peroxide. The advantages of these processes are the safe and environmentallybenign nature of reagents and relatively simple operating principles as well as short reaction time and the absence of mass transfer limitations. The photo-Fenton process is similar to the Fenton process but it offers higher removal efficiencies by employing irradiation. In this process, the generation of hydroxyl radicals accelerates in comparison with the "simple" Fenton process [6].

Studies involving the removal of MET and DIC from aqueous solutions and detailed information regarding the overall degradation process are scarce. Therefore, the present study aims to investigate MET and DIC degradation in aqueous medium induced by $\mathrm{UV}$ and $\mathrm{UV} / \mathrm{H}_{2} \mathrm{O}_{2}$ processes in laboratory photo reactor. The solutions toxicity was evaluated with a Vibrio fischeri assay.

\section{Materials and Methods}

\subsection{Chemicals}

Metformin hydrochloride and diclofenac sodium salt (initial concentration, $\mathrm{C} 0=10 \mathrm{mg} / \mathrm{L}$ ) with a purity of over $99 \%$ were used. Their main physico-chemical characteristics are presented in Table 1. Hydrogen-peroxide $(30 \% w / w)$ was also used as received. Solvents for analytical determination were methanol and dichlormethane (J.T. Baker). Stock solutions of pharmaceuticals and other solutions were prepared in deionized water (DI) and diluted as required.

Table 1. Physico-chemical characteristics of diclofenac and metformin [7].

Substance

\subsection{Preparation of the Synthetic Solution and Experimental Procedure}

Diclofenac and metformin stock solutions $(1000 \mathrm{mg} / \mathrm{L})$ were prepared weekly using DI water and stored in the dark at $4{ }^{\circ} \mathrm{C}$. UV irradiation was provided by a Pen Ray lamp emission at $254 \mathrm{~nm}$ which was covered with a quartz tube and placed in the middle of the reactor. During photolytic experiments, temperature was maintained at $25{ }^{\circ} \mathrm{C}$ by using external water cooling around the reactor. Experimental conditions of the process were: [DIC, MET] $=10 \mathrm{mg} / \mathrm{L},\left[\mathrm{H}_{2} \mathrm{O}_{2}\right]=2.5 \mathrm{mM}$, reaction time $3 \mathrm{~h}$. 


\subsection{Analytical Procedure}

The efficiency removals were monitored using UV/VIS spectrophotometer (Shimadzu UV-1800, Japan). DCF and MET concentration were measured at $\lambda=276$ and $232 \mathrm{~nm}$, respectively. The toxicity test for bacteria Vibrio fischeri was done according to ISO 11348-1: 2008 Water quality-Determination of the inhibitory effect of water samples on the light emission of Vibrio fischeri (Luminiscent bacteria test) [8].

\section{Results and Discussion}

Results obtained by only UV exposition of solution showed that diclofenac and metformin were degradated $30 \%$ and $50 \%$ during $3 \mathrm{~h}$ test. Addition of $2.5 \mathrm{mM} \mathrm{H}_{2} \mathrm{O}_{2}$ to photo reactor contributed to $90 \%$ and $100 \%$ removal of DCF and MET, respectively (Table 2).

Table 2. Results of efficiency removals of DIC and MET after UV treatments.

\begin{tabular}{ccc}
\hline \multirow{2}{*}{ Treatment } & \multicolumn{2}{c}{ Removals (\%) } \\
\cline { 2 - 3 } & Diclofenac & Metformin \\
\hline $\mathrm{UV}$ & 30 & 50 \\
$\mathrm{UV} / \mathrm{H}_{2} \mathrm{O}_{2}$ & 90 & 100 \\
\hline
\end{tabular}

The full spectra of both pharmaceuticals during the treatments were presented in Figure 1. As it can be seen from the spectra, $3 \mathrm{~h}$ of treatment is proved to be enough for degradation of diclofenac, especially after $\mathrm{UV} / \mathrm{H}_{2} \mathrm{O}_{2}$ process. Although, similar conclusion could be retrieved for metformin, after both, UV and $\mathrm{UV} / \mathrm{H}_{2} \mathrm{O}_{2}$ treatments, higher peaks appeared in the lower UV region, indicating transformation of metformin to other organic compounds.

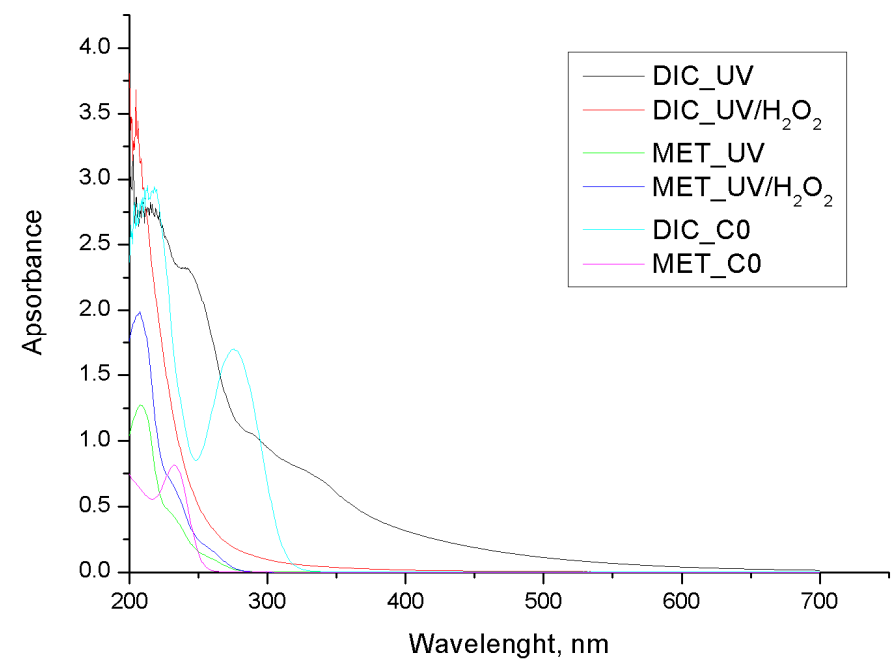

Figure 1. Absorption UV/VIS spectra of investigated pharmaceuticals.

Inhibition toxicity test of MET increased in the following range: 13\% (C0) $<38 \%$ (UV) $<77 \%$ $\left(\mathrm{UV} / \mathrm{H}_{2} \mathrm{O}_{2}\right)$, while toxicity measured for DCF solutions followed the range: $33 \%$ (UV) $<75 \%(\mathrm{C} 0)<$ $78 \%\left(\mathrm{UV} / \mathrm{H}_{2} \mathrm{O}_{2}\right)$ (Table 3). One can conclude that degradation products of metformin are more toxic than the parent compound. Similar conclusions were confirmed by other authors in the case of different organic compounds [6]. In the case of diclofenac, its initial concentration and $\mathrm{UV} / \mathrm{H}_{2} \mathrm{O}_{2}$ byproduct had similar toxicity $(75-78 \%)$, while UV irradiation decreased its initial toxicity from $75 \%$ to $33 \%$. 
Table 3. Results of toxicity inhibition tests of DIC and MET after UV treatments.

\begin{tabular}{ccc}
\hline \multirow{2}{*}{ Treatment } & \multicolumn{2}{c}{ Toxicity inhibition (\%) } \\
\cline { 2 - 3 } & Diclofenac & Metformin \\
\hline Initial concentration, (C0) & 75 & 13 \\
$\mathrm{UV}$ & 33 & 38 \\
$\mathrm{UV} / \mathrm{H}_{2} \mathrm{O}_{2}$ & 78 & 77 \\
\hline
\end{tabular}

\section{Conclusions}

In this paper, the degradation of metformin and diclofenac in aqueous solution under UV irradiation was investigated in a lab-scale photo reactor. The results confirmed that addition of hydrogen-peroxide accelerated the removal of investigated pharmaceuticals, but at the same time, lead to formation of the more toxic intermediates. The possible reason for better removal efficiency of metformin can be related to its simpler aliphatic structure in comparison to more aromatic diclofenac.

Author Contributions: A.L.M. and M.B.-T. designed the experiment. Đ.K. and D.T.P. helped with the data analysis. J.J. performed the experiments. A.K. performed toxicity tests and data analysis. B.D. contributed reagents and materials.

Acknowledgments: The authors acknowledge the financial support of the Ministry of Education, Science and Technological Development of the Republic of Serbia within the Project III43005.

We acknowledge the National Library of Medicine (NLM) for information on physico-chemical characteristics of pharmaceuticals.

Conflicts of Interest: The authors declare no conflict of interest.

\section{References}

1. Bagheri, S.; TermehYousefi, A.; Do, T. Photocatalytic pathway toward degradation of environmental pharmaceuticals pollutants: Structure, kinetics and mechanism approach. Catal. Sci. Technol. 2017, 7, 45484569 .

2. Zhu, S.; Liu, Y.; Liu, S.; Zeng, G.; Jinag, L.; Tan, X.; Zhou, L.; Zeng, W.; Li, T.; Yang, C. Adsorption of emerging contaminant metformin using graphene oxide. Chemospere 2017, 179, 20-28.

3. Perisic, D.J.; Gilja, V.; Stankov, M.N.; Katancic, Z.; Kusic, H.; Stangar, U.L.; Dionysiou, D.D.; Bozic, A.L. Removal of diclofenac from water by zeolite-assisted advanced oxidation processes. J. Photochem. Photobiol. A 2016, 321, 238-247.

4. Briones, R.M.; Sarmah, A.K.; Padhye, L.P. A global perspective on the use, occurrence, fate and effects of antidiabetic drug metformin in natural and engineered ecosystems. Environ. Pollut. 2016, 219, 1007-1020.

5. Safari, G.H.; Hosefini, M.; Seyedsalehi, M.; Kamani, H.; Jaafari, J.; Mahvi, A.H. Photocatalytic degradation of tetracycline using nanosized titanium dioxide in aqueous solution. Int. J. Environ. Sci. Technol. 2015, 12, 603-616.

6. Mirzaei A.; Chen, Z.; Haghighat, F.; Yerushalmi, L. Removal of pharmaceuticals from water by homo/heterogonous Fenton-type processes-A review. Chemosphere 2017, 174, 665-688.

7. Toxicology Data Network. Available online: https://toxnet.nlm.nih.gov/ (accessed on 1 June 2018).

8. ISO 11348-1: 2008 Water Quality-Determination of the Inhibitory Effect of Water Samples on the Light Emission of Vibrio fischeri (Luminiscent Bacteria Test); British Standards Institution: London, UK, 2008. 